\title{
CARACTERIZAÇÃO DE BEBIDAS LÁCTEAS FUNCIONAIS FERMENTADAS POR PROBIÓTICOS E ACRESCIDAS DE PREBIÓTICO ${ }^{1}$
}

\author{
Karime Gianetti THAMER ${ }^{2}$, Ana Lúcia Barretto PENNA ${ }^{2, *}$
}

\begin{abstract}
RESUMO
A busca pela alimentação mais saudável, aliada ao aproveitamento do soro pelas indústrias de laticínios, torna favorável a elaboração de bebidas lácteas fermentadas à base de soro de leite. O objetivo deste trabalho foi caracterizar bebidas lácteas funcionais fermentadas por probióticos e acrescidas de prebiótico, elaboradas conforme 12 tratamentos. As amostras foram submetidas a análises de pH, acidez, gordura, sólidos totais, proteínas, cinzas e carboidratos. O valor de $\mathrm{pH}$ 4,8 foi um parâmetro adequado para finalizar a fermentação das bebidas, garantindo assim a viabilidade dos probióticos. Houve variação na composição centesimal das bebidas lácteas conforme a formulação. Quanto maior o teor de soro, menor a acidez titulável e menor o teor de proteínas. As bebidas lácteas apresentaram os maiores teores de sólidos totais e de carboidratos, quando formuladas com as maiores porcentagens de açúcar e frutooligossacarídeos. Os menores teores de cinzas foram observados nas bebidas elaboradas com os maiores teores de açúcar. As amostras atenderam à legislação brasileira em vigor, sendo os produtos considerados desnatados por apresentarem menos de $0,5 \%$ de gordura, independente das formulações.

Palavras-chave: probiótico, prebiótico, bebidas lácteas.
\end{abstract}

\section{SUMMARY}

CHARACTERIZATION OF FUNCTIONAL DAIRY BEVERAGES FERMENTED BY PROBIOTICS AND WITH THE ADDITION OF PREBIOTICS. The attempt to find healthier foods combined with the use of whey by the dairy industry has favored the production of fermented dairy beverages based on milk whey. The aim of this research is to characterize functional dairy beverages fermented by probiotics which have a prebiotic supplement added and which have been developed according to 12 treatments. The samples were analysed for the $\mathrm{pH}$, acidity, fat content, total solids, protein, ashes and carbohydrates. The $\mathrm{pH}$ value of 4.8 was a suitable parameter to complete the fermentation of the beverages, thus ensuring the viability of probiotics. There was a variation in the centesimal composition of the dairy beverages according to the formulation. The higher the whey content, the lower the titratable acidity and the lower the protein content. The dairy beverages showed the highest total solids and carbohydrate contents when formulated with higher percentages of sugar and fructooligossacharides. The lower ash contents were observed in the beverages prepared with the highest sugar contents. The samples complied with current Brazilian legislation, and the products were considered nonfat because they presented less than $0.5 \%$ fat, regardless of the formulations.

Keywords: probiotic, prebiotic, dairy beverages.

\section{1 - INTRODUÇÃO}

O uso dos alimentos como veículo de promoção do bem-estar e saúde e, ao mesmo tempo, como redutor dos riscos de algumas doenças, tem incentivado as pesquisas de novos componentes naturais e o desenvolvimento de novos ingredientes, possibilitando a inovação em produtos alimentícios e a criação de novos nichos de mercado [20]. A indústria de laticínios está reagindo para aumentar a sua competitividade no segmento de produtos funcionais, para se adaptar à tendência de mudanças em um mercado consumidor exigente, que se modifica rapidamente, além de ter que manter a liderança tecnológica na indústria de alimentos [8, 27]. O interesse por produtos alimentícios saudáveis, nutritivos e de grande aproveitamento tem crescido mundialmente, o que resulta em diversos estudos na área de produtos lácteos. Alguns desses estudos têm dado ênfase

${ }^{1}$ Recebido para publicação em 28/6/2005. Aceito para publicação em 6/7/2006 (001563)

${ }^{2}$ Departamento de Engenharia e Tecnologia de Alimentos,

Rua Critóvão Colombo, 2265, CEP 15054-000, São José do Rio Preto (SP)

E-mail:analucia@ibilce.unesp.br

* A quem a correspondência deve ser enviada ao valor nutricional dos ingredientes lácteos, assim como à importância de uma dieta baseada em produtos lácteos.

O alimento funcional, além de suas funções nutricionais como fonte de energia e de substrato para a formação de células e tecidos, possui em sua composição uma ou mais substâncias que atuam modulando e ativando os processos metabólicos, melhorando as condições de saúde pelo aumento da efetividade do sistema imune, promovendo o bem-estar das pessoas e prevenindo o aparecimento precoce de alterações patológicas e de doenças degenerativas, que levam a uma diminuição da longevidade [25, 29].

Os principais ingredientes responsáveis pela funcionalidade desses produtos são liderados pelas fibras dietéticas, óleos de peixe, esteróis de plantas, minerais, vitaminas, prebióticos e probióticos [15]. A indústria também tem utilizado outros ingredientes opcionais, como os substitutos de gorduras e edulcorantes, dependendo do tipo de produto que se quer produzir e do público alvo [4, 13, 33].

Certos carboidratos, oligossacarídeos e polissacarídeos ocorrem naturalmente e podem ser usados como prebióticos [4]. Os oligossacarídeos constituem um grupo bastante enfatizado, e dentre os benefícios de sua ingestão estão o aumento da população das bifidobactérias no cólon, que por 
seu efeito antagônico suprimem a atividade das bactérias putrefativas e reduzem a formação de produtos tóxicos da fermentação. Previnem, ainda doenças patogênicas, diarréia e prisão de ventre, protegem as funções do fígado, reduzem o colesterol e a pressão sanguínea, possuem efeitos anticarcinogênicos, produzem nutrientes, entre outros [36].

A procura do consumidor brasileiro por produtos mais saudáveis, inovadores, seguros e de prática utilização, aliada à consolidação dos produtos no mercado, contribuíram para o crescimento da indústria de bebidas lácteas, fazendo com que estas ganhassem popularidade [19]. A produção de bebida láctea adicionada de soro de queijo em sua formulação vem ganhando um mercado muito grande, principalmente com o maior nível de informação sobre a importância do cálcio, a qualidade das proteínas, o papel dos componentes bioativos e das bactérias probióticas para a saúde, do custo do produto para o fabricante e do preço final para o consumidor [13, 14, 24, 28, 38].

O termo "bebidas lácteas" tem sentido amplo e pode englobar uma série de produtos fabricados com leite e soro. Bebida láctea é o produto lácteo resultante da mistura do leite (in natura, pasteurizado, esterilizado, UHT, reconstituído, concentrado, em pó, integral, semidesnatado ou parcialmente desnatado e desnatado) e soro de leite (líquido, concentrado ou em pó) adicionado ou não de produto(s) alimentício(s) ou substância alimentícia, gordura vegetal, leite(s) fermentado(s), fermentos lácteos selecionados e outros produtos lácteos. A base láctea representa pelo menos $51 \%$ (cinqüenta e um por cento) massa/massa $(\mathrm{m} / \mathrm{m}$ ) do total de ingredientes do produto, fermentado mediante a ação de cultivo de microrganismos específicos e/ou adicionado de leite(s) fermentado(s) e que não poderá ser submetido a tratamento térmico após a fermentação. A contagem total de bactérias lácticas viáveis deve ser no mínimo de $10^{6} \mathrm{UFC} / \mathrm{g}$ no produto final, para o(s) cultivo(s) láctico(s) específico(s) empregado(s), durante todo o prazo de validade [9]. As bebidas lácteas podem conter em sua formulação, além do soro, do leite e dos cultivos de bactérias lácticas já tradicionais, acidulantes, aromatizantes, reguladores de acidez, estabilizantes, espessantes, emulsificantes, corantes, conservantes, pedaços, polpa ou sucos de frutas e mel.

As bebidas lácteas contêm proteínas, gorduras, lactose, minerais e vitaminas, sendo consideradas nutritivas. A importância da porcentagem de gordura no produto final está relacionada ao fato de que as pessoas cada vez mais estão à procura de uma alimentação mais saudável, incluindo os alimentos diet e light. Além dos cuidados com a saúde (alimentos funcionais), existem os cuidados e preocupações com a estética corporal, assunto tão explorado nos últimos anos.

A demanda dos consumidores por alimentos funcionais impulsionou a expansão de produtos como iogurtes líquidos e outras bebidas lácteas, bebidas à base de soja, bebidas isotônicas/energéticas, atingindo a quarta maior taxa de crescimento entre 2000 e 2001 , de $10 \%$ para $12 \%$. Esse crescimento é influenciado pela conveniência e praticidade, saúde e segurança. Na categoria iogurtes líquidos, houve o lançamento de diversos novos produtos, sabores e embala- gens inovadoras. Com mais alternativas de bebidas lácteas e de soja entrando no mercado, esta categoria combinada apresentou significativa atividade de novos produtos [23]. Além disso, na última década, têm se intensificado as pesquisas relacionadas às bebidas lácteas funcionais. Dentre elas, podem ser citadas as realizadas por ALMEIDA, BONASSI \& ROÇA [1], que avaliaram as características físicas e químicas de bebidas lácteas fermentadas com culturas probióticas e preparadas com soro de queijo minas frescal. PINHEIRO [26], utilizando uma cultura contendo S. thermophilus, L. bulgaricus, L. acidophilus e Bifidobacterium, elaboraram iogurtes probióticos com edulcorantes. SILVA et al. [30] elaboraram uma bebida láctea fermentada com cultura probiótica, à base de soro de queijo, fortificada com ferro aminoácido quelato, e avaliaram as características físico-químicas, microbiológicas, nutricionais e sensoriais. O produto foi considerado um adequado veículo alimentar para suplementação com ferro.

As propriedades funcionais dos produtos de soro são de grande importância para os fabricantes de produtos lácteos fermentados com características probióticas ou nutracêuticas. Os produtos de soro não só permitem ao fabricante reduzir o custo total dos ingredientes como também apresentam a importante vantagem de possuírem propriedades funcionais excepcionais, além de serem uma fonte concentrada de nutrientes lácteos, sobretudo proteínas de elevado valor nutricional e cálcio [17].

Neste contexto, o desenvolvimento de uma bebida láctea funcional, fermentada com culturas probióticas e acrescida de prebiótico, é uma alternativa bastante inovadora para o aproveitamento do soro pelas indústrias lácteas, sem a necessidade de grandes investimentos ou de grandes mudanças na rotina de fabricação. Assim, as indústrias também diminuem o desperdício, a poluição ambiental, gerando novos recursos e, principalmente, melhoram o valor nutritivo deste produto.

O presente trabalho teve como objetivo caracterizar bebidas lácteas funcionais fermentadas por probióticos e acrescidas de prebiótico, elaboradas conforme 12 tratamentos.

\section{2 - MATERIAL E MÉTODOS}

\section{1 - Caracterização do leite e do soro para a fabricação das bebidas lácteas}

O leite em pó e o soro de leite em pó foram reconstituídos em água a $12,28 \%$ de sólidos totais e submetidos às determinações, em triplicata. As medidas dos valores de $\mathrm{pH}$ foram feitas em potenciômetro digital [18]. Os teores de acidez foram determinados pela titulação ácido-alcalimétrica, usando-se fenolftaleína como indicador [31]. As determinações de gordura foram feitas pelo método de Gerber [10]. Os teores de sólidos totais foram determinados pela secagem da amostra em estufa a vácuo a $70^{\circ} \mathrm{C}$ por $24 \mathrm{~h}$ [10]. A verificação da presença de resíduos de antibióticos do grupo $\beta$-lactâmicos foi feita pelo teste Snap [37]. 


\section{2 - Preparação da cultura láctea}

A cultura mista liofilizada MY BIO 6 (Ezal-Rhodia), contendo Streptococcus thermophilus, Lactobacillus delbrueckii subsp. bulgaricus, Bifidobacterium e Lactobacillus acidophilus, foi dissolvida assepticamente em um litro de leite desnatado esterilizado e resfriado a $5{ }^{\circ} \mathrm{C}$ para, em seguida, ser distribuída em frascos esterilizados. Os frascos foram mantidos em congelador à temperatura de - $18{ }^{\circ} \mathrm{C}$. Na ocasião do uso, foram descongelados e a cultura, inoculada diretamente na mistura de leite e soro, para a fabricação da bebida láctea.

\section{3 - Preparação das bebidas lácteas}

O leite em pó desnatado (Nestlé) e o soro de leite em pó (Sweetmix) foram misturados, conforme o experimento, totalizando aproximadamente $8 \%$ de sólidos totais, adicionados de açúcar e de frutooligossacarídeos (Nutra Flora P-95), reconstituídos em água e acrescidos de 0,4\% de estabilizante SBB 280 (Danisco Cultor), sob agitação constante e vigorosa. Esta mistura foi aquecida até $85{ }^{\circ} \mathrm{C}$ e mantida por $20 \mathrm{~min}$ em banho termostatizado. A mistura foi resfriada em banho de água e gelo até atingir $42{ }^{\circ} \mathrm{C}$, para receber a cultura láctica em condições assépticas. O produto foi incubado a $42{ }^{\circ} \mathrm{C}$. O tempo de fermentação da bebida láctea foi calculado a partir do início da inoculação, até obter-se o valor de $\mathrm{pH}$ próximo a 4,7-4,8. Terminada a fermentação, foi feito um resfriamento inicial até $20^{\circ} \mathrm{C}$, aproximadamente, e a quebra do coágulo, durante $30 \mathrm{~s}$ por agitação manual, seguida por resfriamento final em banho de água e gelo. A bebida foi embalada em copos plásticos e armazenada em refrigerador à temperatura de $5{ }^{\circ} \mathrm{C}$, aproximadamente.

\section{4 - Planejamento estatístico dos experimentos e análise dos resultados}

Foram feitas diferentes formulações da bebida láctea, variando-se as concentrações de soro (45\%, 50\% e 55\%) em substituição ao leite em pó, de açúcar (6\%, 7\% e $8 \%$ ) e de frutooligossacarídeos ( $1 \%, 2 \%$ e $3 \%)$. A concentração do estabilizante foi mantida fixa em todas as formulações e todas elas seguiram a mesma seqüência de fabricação.

Os ensaios foram realizados segundo um planejamento experimental do tipo fatorial com dois níveis e 3 fatores $\left(2^{3}\right)$ e quatro pontos centrais [21]. A Tabela 1 mostra as variáveis independentes e os níveis das variações que foram usados nos 12 experimentos.

O ponto central codificado como "0" foi selecionado após testes preliminares e segundo dados disponíveis na literatura. Os níveis de variação codificados como - 1 e 1 foram escolhidos para cobrir a região experimental conveniente.

Foi feita a análise de variância (ANOVA) dos resultados das amostras e a comparação entre médias pelo teste de Tukey, utilizando-se o programa computacional ESTAT, desenvolvido por BANZATTO \& KRONKA [3]. Para as análises foi considerado um nível de significância de $5 \%$ $(\mathrm{p}<0,05)$.
TABELA 1 - Planejamento experimental - Matriz de ensaios para o projeto fatorial fracionado com as variáveis nas unidades codificadas e originais.

\begin{tabular}{crrrccc}
\hline Experimentos & $\mathbf{X}_{1}$ & \multicolumn{1}{c}{$\mathbf{X}_{2}$} & $\mathbf{X}_{3}$ & $\mathbf{S}(\%)$ & $\mathbf{A ~ ( \% )}$ & FOS (\%) \\
\hline 1 & $-1,00$ & $-1,00$ & $-1,00$ & 45,0 & 6,0 & 1,0 \\
2 & 1,00 & $-1,00$ & $-1,00$ & 55,0 & 6,0 & 1,0 \\
3 & $-1,00$ & 1,00 & $-1,00$ & 45,0 & 8,0 & 1,0 \\
4 & 1,00 & 1,00 & $-1,00$ & 55,0 & 8,0 & 1,0 \\
5 & $-1,00$ & $-1,00$ & 1,00 & 45,0 & 6,0 & 3,0 \\
6 & 1,00 & $-1,00$ & 1,00 & 55,0 & 6,0 & 3,0 \\
7 & $-1,00$ & 1,00 & 1,00 & 45,0 & 8,0 & 3,0 \\
8 & 1,00 & 1,00 & 1,00 & 55,0 & 8,0 & 3,0 \\
9 & 0,00 & 0,00 & 0,00 & 50,0 & 7,0 & 2,0 \\
10 & 0,00 & 0,00 & 0,00 & 50,0 & 7,0 & 2,0 \\
11 & 0,00 & 0,00 & 0,00 & 50,0 & 7,0 & 2,0 \\
12 & 0,00 & 0,00 & 0,00 & 50,0 & 7,0 & 2,0 \\
\hline S = teor de soro; A & teor de açúcar; e FOS $=$ teor de frutooligossacarídeos.
\end{tabular}

\section{5 - Caracterização físico-química das bebidas lácteas funcionais}

As bebidas lácteas foram avaliadas em triplicata. As medidas dos valores de $\mathrm{pH}$ foram feitas em potenciômetro digital [18]. As determinações dos teores de acidez foram realizadas pela titulação ácido-alcalimétrica, usando-se fenolftaleína como indicador [31]. Os teores de gordura foram determinados pelo método de Gerber [10]. Os teores de sólidos totais foram determinados pela secagem da amostra em estufa a vácuo a $70{ }^{\circ} \mathrm{C}$ por $24 \mathrm{~h}$ [10]. As análises de proteínas foram realizadas baseando-se na determinação do nitrogênio pelo método de micro-Kjeldahal. O teor de proteínas foi calculado multiplicando-se o valor de nitrogênio por 6,38 [2]. A determinação das cinzas foi feita pela incineração da amostra em mufla a $550{ }^{\circ} \mathrm{C}$ [18]. O teor de carboidratos foi calculado pela diferença entre os sólidos totais e o somatório dos teores de gordura, proteínas e cinzas.

\section{3 - RESULTADOS E DISCUSSÃO}

\section{1 - Caracterização do leite e do soro para a fabricação das bebidas lácteas}

A Tabela 2 apresenta os resultados obtidos nas análises do leite em pó e do soro de queijo em pó reconstituídos. Segundo HUGUNIN [17], o leite em pó desnatado e o soro doce em pó apresentam, antes da reconstituição, em média, $1 \%$ de gordura e $3,4 \%$ e $4,5 \%$ de umidade, respectivamente.

TABELA 2 - Caracterização do leite desnatado reconstituído e soro de queijo em pó.

\begin{tabular}{lccc}
\hline \multicolumn{1}{c}{ Análises } & Unidades & Leite em pó & Soro em pó \\
\hline $\mathrm{pH}$ & - & 6,44 & 6,38 \\
Acidez & ${ }^{\circ}$ & 25,08 & 17,19 \\
Gordura & $\%$ & 0,07 & 0,03 \\
Sólidos totais & $\%$ & 12,24 & 12,20 \\
Antibióticos & - & negativo & negativo \\
\hline
\end{tabular}


Os resultados mostram que o leite em pó desnatado e o soro de queijo em pó apresentaram características adequadas para a elaboração das bebidas lácteas.

\section{2 - Caracterização físico-química das bebidas lácteas}

A Tabela 3 mostra os resultados da caracterização físicoquímica (tempo de fermentação, valor de $\mathrm{pH}$, acidez, teores de gordura, sólidos totais, proteínas, cinzas e carboidratos) realizada nas bebidas lácteas experimentais.

Os tempos de fermentação variaram de 180 a 255 min, muito próximos entre os tratamentos, porém a diferença nos teores de soro, açúcar e frutooligossacarídeos podem ter influenciado ligeiramente o tempo de fermentação. PINHEIRO [26], utilizando a cultura contendo S. thermophilus, $L$. bulgaricus, L. acidophilus e Bifidobacterium, obteve um valor médio de 315 min na elaboração de iogurtes probióticos com edulcorantes. Entretanto, TAMIME \& ROBINSON [35], consideram que, na faixa de $40-45{ }^{\circ} \mathrm{C}$, o período de incubação pode variar de 2,5 a $5 \mathrm{~h}$.

Os valores do presente estudo aproximam-se bastante dos encontrados por DAVE \& SHAH [12], que obtiveram tempos de fermentação que variaram de 3,5 a $6,0 \mathrm{~h}$, utilizando culturas lácteas mistas compostas de Streptococcus thermophilus, Lactobacillus delbrueckii subsp. bulgaricus, Lactobacillus acidophilus e Bifidobacterium na fabricação de iogurtes.

Apesar da fermentação ter sido encerrada e iniciado o resfriamento em $\mathrm{pH} 4,8$, os valores de $\mathrm{pH}$ encontrados nos doze tratamentos no término da fermentação e resfriamento variaram entre 4,72 e 4,83. O controle de pH é importante no processo de fermentação, pois a separação do soro está diretamente relacionada com este parâmetro. Embora em produtos com pH maior que 4,6, a coalhada não seja suficientemente formada, favorecendo a sinérese [7], ela não foi observada nos doze tratamentos. Além disso, a fermentação continua muito lentamente durante o resfriamento, assim, iniciando-se o resfriamento em $\mathrm{pH}$ igual a 4,8, evita-se o abaixamento excessivo do $\mathrm{pH}$. Por outro lado, em produtos com pH menor que 4,0, ocorre separação do soro devido à redução da hidratação das proteínas e contração do coágulo [7]. GURGEL \& OLIVEIRA [16] observaram uma diminuição mais acentuada dos valores de $\mathrm{pH}$, de 4,06 a 4,39, em temperaturas mais elevadas durante o tempo de armazenamento de iogurtes. Isso fez com que diminuísse a aceitação do produto. Nos experimentos realizados com bebidas lácteas, atingiram-se valores próximos a 4,8 , superiores aos relatados pelos autores acima citados.

As diferenças nos valores de $\mathrm{pH}$ nos diferentes produtos podem estar relacionadas ao tipo e porcentagem de cultura utilizada, à atividade desta cultura, ao valor estabelecido para finalizar a fermentação, à quantidade de soro de leite utilizada na elaboração das bebidas lácteas, à adição de diferentes ingredientes, assim como ao tempo de armazenamento.

ALMEIDA, BONASSI \& ROÇA [1], ao desenvolverem bebidas lácteas fermentadas com o mesmo tipo de cultura mista comercial utilizada neste trabalho e com concentrações de soro lácteo variando de $30 \%$ a $50 \%$, estabeleceram um tempo de fermentação de 4 a 4,5 h e encontraram valores de $\mathrm{pH}$ entre 4,5 e 5,0, muito próximos aos resultados encontrados nos doze experimentos realizados.

O valor do pH tem sua importância relacionada também com o aspecto visual do produto final durante sua conservação em temperaturas baixas. É fundamental que haja um controle rigoroso para que não ocorram possíveis separações de fases, acidificação elevada, influenciada pelo tempo de fermentação, além de alterações nas características sensoriais que poderão tornar o produto indesejável. Como o $\mathrm{pH}$ interfere na viabilidade da microflora probiótica em leites fermentados, com o decréscimo deste, ocorre uma redução nas contagens de células viáveis de Lactobacillus acidophilus e Bifidobacterium durante a estocagem refrigerada de iogurtes [39].

A acidez titulável, determinada em graus Dornic, variou entre 44,33 e $50,39^{\circ} \mathrm{D}$. Estes valores são muito inferiores

TABELA 3 - Caracterização físico-química das diferentes formulações de bebidas lácteas.

\begin{tabular}{|c|c|c|c|c|c|c|c|c|}
\hline Exp. & $\begin{array}{c}\text { Tempo de } \\
\text { Fermentação (min) }\end{array}$ & Valor de $\mathrm{pH}$ & $\begin{array}{c}\text { Acidez } \\
\left({ }^{\circ} \mathrm{D}\right)\end{array}$ & $\begin{array}{c}\text { Gordura } \\
(\%)\end{array}$ & $\begin{array}{c}\text { Sólidos Totais } \\
(\%)\end{array}$ & $\begin{array}{c}\text { Proteínas } \\
(\%)\end{array}$ & $\begin{array}{c}\text { Cinzas } \\
(\%)\end{array}$ & $\begin{array}{c}\text { Carboidratos } \\
(\%)\end{array}$ \\
\hline 1 & 185 & $4,83 \pm 0,01^{a}$ & $50,39 \pm 0,11^{a}$ & $0,0 \pm 0,0^{a}$ & $15,70 \pm 0,05^{g}$ & $2,15 \pm 0,09^{b c}$ & $0,61 \pm 0,01^{a}$ & $12,94 \pm 0,11^{e}$ \\
\hline 2 & 182 & $4,83 \pm 0,01^{a}$ & $45,52 \pm 0,12^{\mathrm{e}}$ & $0,1 \pm 0,1^{a}$ & $15,68 \pm 0,03^{g}$ & $2,09 \pm 0,04^{\text {bcde }}$ & $0,60 \pm 0,01^{a b c}$ & $12,93 \pm 0,03^{e}$ \\
\hline 3 & 224 & $4,82 \pm 0,01^{a}$ & $49,37 \pm 0,20^{b}$ & $0,1 \pm 0,0^{\mathrm{a}}$ & $17,38 \pm 0,03^{c d e}$ & $2,46 \pm 0,08^{a}$ & $0,55 \pm 0,01^{\mathrm{de}}$ & $14,27 \pm 0,07^{d}$ \\
\hline 4 & 222 & $4,83 \pm 0,00^{a}$ & $46,59 \pm 0,20^{d}$ & $0,1 \pm 0,1^{\mathrm{a}}$ & $17,21 \pm 0,11^{\text {ef }}$ & $1,96 \pm 0,05^{\mathrm{ef}}$ & $0,54 \pm 0,02^{\mathrm{e}}$ & $14,64 \pm 0,14^{b c}$ \\
\hline 5 & 180 & $4,80 \pm 0,01^{\mathrm{b}}$ & $46,92 \pm 0,12^{\mathrm{d}}$ & $0,0 \pm 0,1^{a}$ & $17,49 \pm 0,08^{\mathrm{bc}}$ & $2,17 \pm 0,07^{b}$ & $0,61 \pm 0,01^{\mathrm{ab}}$ & $14,68 \pm 0,13^{b c}$ \\
\hline 6 & 182 & $4,82 \pm 0,01^{a}$ & $45,58 \pm 0,20^{\mathrm{e}}$ & $0,0 \pm 0,0^{a}$ & $17,37 \pm 0,02^{\text {cde }}$ & $1,98 \pm 0,02^{f}$ & $0,58 \pm 0,01^{\mathrm{bcd}}$ & $14,87 \pm 0,03^{b}$ \\
\hline 7 & 255 & $4,80 \pm 0,01^{b}$ & $49,64 \pm 0,12^{b}$ & $0,0 \pm 0,1^{a}$ & $18,95 \pm 0,02^{a}$ & $2,12 \pm 0,02^{\mathrm{bcd}}$ & $0,54 \pm 0,01^{\mathrm{e}}$ & $16,26 \pm 0,08^{a}$ \\
\hline 8 & 180 & $4,72 \pm 0,01^{\mathrm{e}}$ & $44,33 \pm 0,12^{f}$ & $0,1 \pm 0,1^{a}$ & $18,97 \pm 0,09^{a}$ & $2,02 \pm 0,02^{\text {cdef }}$ & $0,56 \pm 0,02^{\text {cde }}$ & $16,27 \pm 0,15^{a}$ \\
\hline 9 & 222 & $4,77 \pm 0,01^{d}$ & $48,31 \pm 0,12^{c}$ & $0,1 \pm 0,0^{a}$ & $17,57 \pm 0,07^{b}$ & $2,17 \pm 0,06^{b}$ & $0,55 \pm 0,01^{\mathrm{e}}$ & $14,75 \pm 0,11^{b c}$ \\
\hline 10 & 214 & $4,77 \pm 0,01^{\mathrm{cd}}$ & $48,38 \pm 0,11^{c}$ & $0,0 \pm 0,1^{a}$ & $17,07 \pm 0,04^{f}$ & $1,99 \pm 0,03^{\text {def }}$ & $0,58 \pm 0,00^{a b c d}$ & $14,47 \pm 0,05^{c c}$ \\
\hline 11 & 252 & $4,78 \pm 0,01^{b c}$ & $49,44 \pm 0,23^{b}$ & $0,0 \pm 0,0^{a}$ & $17,38 \pm 0,03^{c d}$ & $2,08 \pm 0,02^{\text {bcde }}$ & $0,55 \pm 0,01^{\mathrm{de}}$ & $14,76 \pm 0,06^{b c}$ \\
\hline 12 & 216 & $4,78 \pm 0,00^{\mathrm{cd}}$ & $48,18 \pm 0,20^{c}$ & $0,1 \pm 0,1^{\mathrm{a}}$ & $17,24 \pm 0,07^{\text {def }}$ & $2,18 \pm 0,04^{b}$ & $0,53 \pm 0,01^{\mathrm{e}}$ & $14,45 \pm 0,17^{c c}$ \\
\hline
\end{tabular}


aos observados em iogurtes, de 60 a $150{ }^{\circ} \mathrm{D}$. Os maiores valores foram observados quando foram utilizados os menores teores de soro de leite (45\%), de açúcar (6\%) e de FOS ( $1 \%)$, ou seja, quanto maior o teor de sólidos totais, menor a acidez titulável. O teor de sólidos também afeta a acidez titulável e o tempo de coagulação devido à ação tamponante dos outros constituintes, como proteínas, citratos, fosfatos e lactatos [34, 5, 32]. Entretanto, WOLFSCHOON-POMBO, GRANZINOLLI \& FERNANDES [40] observaram em iogurtes elaborados com diferentes teores de sólidos totais que, em função do aumento de sólidos totais, a acidez titulável aumentou nitidamente, o que não foi observado neste trabalho, nas diferentes proporções soro-leite, açúcar e FOS utilizadas para elaboração das bebidas lácteas. A acidez titulável está relacionada com o tipo de sólido adicionado, lácteo ou não, e com a atividade da cultura responsável pela fermentação.

A acidez exerce grande influência sobre os atributos de qualidade dos produtos lácteos fermentados e é um dos fatores que limita sua aceitação. Assim, a baixa acidez de todas as bebidas lácteas elaboradas (acidez entre 44,33 e $50,39^{\circ} \mathrm{D}$ ) favorece sua aceitabilidade pelos consumidores. Além disso, a produção de ácido lático, substância característica de todos os leites fermentados, age como conservante natural, além de tornar os componentes do leite mais digeríveis, favorecendo os indivíduos aclorídricos [30]. A produção de ácido lático contribui para a desestabilização das micelas de caseína e, conseqüentemente, para a formação do gel, além de proporcionar o seu sabor ácido característico, podendo também acentuar o aroma do produto. Durante a estocagem refrigerada das bebidas lácteas elaboradas, pode haver aumento da acidez titulável. Estas mudanças na acidez do produto ocorrem, em maior ou menor grau, dependendo da temperatura de refrigeração, do tempo de armazenamento e do poder de pós-acidificação das culturas utilizadas [16] e também se relaciona às mudanças nos valores de $\mathrm{pH}$.

Os teores de gordura das bebidas lácteas variaram entre $0 \%$ e $0,10 \%$, uma vez que se utilizou leite desnatado. A variação entre as porcentagens de gordura nos doze experimentos realizados não apresentou diferença significativa, como mostra o teste de Tukey (Tabela 3). Segundo a legislação brasileira, em função do teor de gordura na base láctea, os leites fermentados são classificados da seguinte forma: a) com creme: mínimo de 6,0\%; b) integral: mínimo de $3,0 \%$; c) parcialmente desnatado: máximo de 2,9\%; e d) desnatado: máximo de 0,5\% [11]. Dessa forma, as bebidas lácteas fermentadas formuladas neste trabalho podem ser enquadradas na categoria de desnatados. Em geral, as bebidas lácteas disponíveis no comércio apresentam baixos teores de gordura. O conteúdo de gordura dos diferentes tipos de iogurte e bebidas lácteas, elaborado em diversas partes do mundo, varia de $0,1 \%$ a $10 \%$, sendo necessário padronizar a composição do leite para cumprir as especificações fixadas pelas normas legais [35, 6].

Com relação ao teor de sólidos totais, quanto maior a porcentagem de sólidos dos ingredientes usados para o preparo das bebidas lácteas, maior será o teor de sólidos totais. Foram obtidos valores entre $15,68 \%$ e $18,97 \%$. Os experimentos 7 e 8 , os quais apresentaram médias mais elevadas, de $18,95 \%$ e $18,97 \%$, respectivamente, continham a concentração máxima de sacarose (8\%) e FOS (3\%). Entre esses dois experimentos não houve diferença significativa pelo teste de Tukey. Os experimentos com médias mais baixas, incluindo os tratamentos 1 e 2, tinham em sua formulação $6,0 \%$ de açúcar e 1,0\% de frutooligossacarídeos, ou seja, os menores níveis das variáveis.

Na elaboração e avaliação de uma bebida láctea fermentada à base de soro de leite fortificada com ferro, SILVA et al. [30] encontraram um teor de 18,16\% de sólidos totais. Esse valor corresponde a uma composição de 58,0\% de leite cru, $24,8 \%$ de soro de queijo, $8,2 \%$ de sacarose, $7,0 \%$ de polpa de manga e $2 \%$ de cultura mista. Os tratamentos 7 e 8 apresentaram resultados mais semelhantes aos da bebida láctea mencionada pelo fato da proximidade entre as quantidades totais de ingredientes.

Nos diferentes tratamentos, foram obtidos produtos com aspecto e consistência variados, em função das quantidades de soro, açúcar e frutooligossacarídeo. A variação destes ingredientes pode ser usada para estabelecer o teor de sólidos totais de acordo com as expectativas do público alvo, conseguindo-se uma maior aceitação.

O teor de proteínas nas bebidas lácteas variou entre $1,93 \%$ e $2,46 \%$, que está diretamente relacionado com a composição da bebida. O maior valor $(2,46 \%)$ corresponde ao experimento 3 , o qual apresenta a menor porcentagem de soro de leite (45\%), enquanto que o experimento 6, com menor teor protéico, apresentou em sua formulação $55 \%$ de soro de leite. Esta variação do teor de proteínas entre os tratamentos pode ser explicada pelas diferentes quantidades de soro e de leite desnatado utilizados na elaboração das bebidas lácteas. Como o soro tem menor teor de proteínas do que o leite, à medida que se aumentou a concentração de soro nas bebidas, menores foram os valores de proteínas encontrados. Apesar do menor teor de proteínas, o valor nutricional do soro é indiscutível. Durante a fabricação do queijo, somente a caseína e a gordura do leite são removidas, restando as proteínas do soro ( $\beta$-lactoglobulina, $\alpha$-lactoalbumina, soroalbumina, imunoglobulinas, proteose-peptonas, lactoferrina e transferrina), várias vitaminas hidrossolúveis (tiamina, riboflavina, ácido pantotênico, vitamina B6 e B12), minerais (cálcio, magnésio, zinco e fósforo) e um alto teor de lactose.

Segundo a legislação, para o produto ser legalmente incluído na classificação de bebida láctea fermentada é necessário atingir um mínimo de 1,2 g de proteína/100 g de produto, valor ultrapassado nas bebidas lácteas experimentais [9]. As bebidas "Cândi-Néctar", elaboradas por NEVES [22], e as elaboradas por SILVA et al. [30], já citadas anteriormente, apresentaram, respectivamente, $2,1 \%$ e $2,12 \%$ de proteínas, mostrando a similaridade de composição das bebidas lácteas desenvolvidas com soro. 
As bebidas lácteas dos diferentes tratamentos apresentaram de $12,93 \%$ a $16,27 \%$ de carboidratos. Como o soro é rico em lactose, quanto maior o teor de soro de leite, açúcar e frutooligossacarídeos, maior o teor de carboidratos. SILVA et al. [30] obtiveram 13,66\% de carboidratos (calculados pela diferença entre o teor de sólidos totais e o somatório dos teores de gordura, proteínas e cinzas).

O teor de cinzas variou entre $0,53 \%$ e $0,61 \%$. O menor teor foi obtido no experimento 12 (0,53\%), sem apresentar diferença significativa com os experimentos 3, 4, 7 e 8, pelo teste de Tukey. As bebidas lácteas preparadas conforme estes experimentos possuem a maior porcentagem de açúcar (8\%) na formulação, comparadas às dos demais experimentos. Com esse maior teor de açúcares, a proporção de cinzas em relação aos sólidos totais diminui. O teor de cinzas obtido foi semelhante ao observado por SILVA et al. [30], 0,58\%, provavelmente por semelhança na composição da bebida.

\section{4 - CONCLUSÕES}

Os resultados obtidos permitiram chegar às seguintes conclusões:

- diferença nos teores de soro, açúcar e frutooligossacarídeos podem ter influenciado ligeiramente o tempo de fermentação;

- o valor de $\mathrm{pH}$ 4,8 foi um parâmetro adequado para finalizar a fermentação das bebidas;

- a acidez da bebida foi influenciada por sua composição. Quanto maior o teor de soro, menor a acidez titulável e o teor de proteínas;

- o teor de sólidos também afeta a acidez titulável e o tempo de coagulação devido à ação tamponante dos outros constituintes, como proteínas, citratos, fosfatos e lactatos; e

- as bebidas lácteas atenderam à legislação brasileira em vigor, sendo os produtos considerados desnatados por apresentarem menos de $0,5 \%$ de gordura, independente das formulações.

\section{5 - REFERÊNCIAS BIBLIOGRÁFICAS}

[1] ALMEIDA, K. E., BONASSI, I. A., ROÇA, R. O. Características físicas e químicas de bebidas lácteas fermentadas e preparadas com soro de queijo minas frescal. Ciência e Tecnologia de Alimentos, São Paulo, v. 2, n. 2, p. 187-192, 2001.

[2] AOAC - ASSOCIATION OF OFFICIAL ANALYTICAL CHEMISTS. Official Methods of Analysis, Washington, $16^{\mathrm{a}}$ ed., 1995.

[3] BANZATTO, D. A., KRONKA, S. D. Experimentação Agrícola. $3^{\circ}$ ed. Jaboticabal: FUNESP, 1995.

[4] BERTERRECHE, J. Prebióticos e probióticos em produtos lácteos. $2^{\circ}$ Simpósio de Tecnologia de Produtos Lácteos - Germinal, 2002.

[5] BRANDÃO, S. C. C. Tecnologia da Fabricação de Iogurte. Revista do Instituto de Laticínios Cândido Tostes, Juiz de Fora, v. 42, n. 250, p. 3-8, 1987.
[6] BRANDÃO, S. C. C. Tecnologia da produção industrial de iogurte. Leite \& Derivados, São Paulo, v. 5, n. 25, p. 24-38, 1995.

[7] BRANDÃO, S. C. C. Tecnologia da produção industrial de iogurte. XXXV Semana do Laticinista - Instituto Cândido Tostes, Juiz de Fora, 1997. 52 p. [Apostila].

[8] BRANDÃO, S. C. C. Novas gerações de produtos lácteos funcionais. Indústria de Laticínios, São Paulo, v. 6, n. 37, p. 64-66, 2002.

[9] BRASIL, Portaria 71. Ministério da Agricultura, Pecuária e Abastecimento. Regulamento Técnico de Identidade e Qualidade de Bebidas Lácteas. Diário Oficial da União de 21/09/2004.

[10] CASE, R. A., BRADLEY JR., R. L. \& WILLIAMS, R. R. Chemical and Physical Methods. In: AMERICAN PUBLIC HEALTH ASSOCIATION. Standard Methods for the Examination of Dairy Products. $15^{\circ} \mathrm{ed}$. Washington, 1985. p. 327-404.

[11] CHR. HANSEN. Tópicos da nova legislação para leites fermentados. Informativo HA-LA Biotec, ano VIII, n. $45,1998$.

[12] DAVE, R. I., SHAH, N.P. Viability of yoghurt and probiotic bacteria in yoghurts made from commercial starter cultures. Internacional Dairy Journal, New York, v. 7, n. 1, p. 31-41, 1997.

[13] FERREIRA, A. C. Breve história e perspectivas para a indústria de laticínios no Brasil. $2^{\circ}$ Simpósio de Tecnologia de Produtos Lácteos - Germinal, 2002.

[14] FERREIRA, A. C. Tendências mercadológicas de produtos lácteos fermentados e bebidas lácteas. In: LERAYER, A. L. S., SALVA, T. J. G., coords. Leites fermentados e bebidas lácticas. Campinas: ITAL, p. 7.21-7.40, 1997.

[15] FERREIRA, C. L. L. F. Tecnologia para produtos lácteos funcionais: probióticos. In: PORTUGAL, J.A.B.; CASTRO, M. C. D.; SILVA, P. H. F. O Agronegócio do Leite e os Alimentos Lácteos Funcionais. Juiz de Fora: EPAMIG - Centro Tecnológico - ILCT, 2001. p. 183-203, 2001.

[16] GURGEL, M. S. C. C. A., OliveirA, A. J. Avaliação das características físico-químicas do iogurte. Leite \& Derivados, São Paulo, v. 4, n. 22, p. 38-43, 1995.

[17] HUGUNIN, A. O uso de produtos de soro em iogurte e produtos lácteos fermentados. Leite \& Derivados, São Paulo, v. 5, n. 49, p. 22-33, 1999.

[18] INSTITUTO ADOLFO LUTZ. Normas Analíticas do Instituto Adolfo Lutz. $3^{\circ}$ ed. v. 1. São Paulo, 1985.

[19] LiMA, S. M. C. G., MADUREIRA, F. C. P., PENNA, A. L. B. Bebidas lácteas: nutritivas e refrescantes. Milkbizz Tecnologia, São Paulo, v. 1, n. 3, p. 4-11, 2002.

[20] MATSUBARA, S. Alimentos Funcionais: uma tendência que abre perspectivas aos laticínios. Revista Indústria de Laticínios, São Paulo, v. 6, n. 34, p. 10-18, 2001.

[21] MONTGOMERY, D. C. Design and Analysis of Experiments. John Wiley \& Sons, Inc., 2001.

[22] NEVES, B. S. Elaboração de bebidas lácteas a base de soro. Leite \& Derivados, São Paulo, n. 10, p. 50-54, 1993. 
[23] NIELSEN, A. C. Os produtos mais quentes do mundo. Informações sobre o crescimento de alimentos e bebidas. Relatório Executivo de Notícias, 2002.

[24] NIELSEN, A. C. Tendência do mercado de iogurtes e bebidas lácteas: evolução dos segmentos. In: LERAYER, A. L. S., SALVA, T. J. G., coords. Leites fermentados e bebidas lácteas. Campinas: ITAL, p. 2.11-2.25, 1997.

[25] PARK, Y. K., KOO, M. H., CARVALHO, P. O. Recentes progressos dos alimentos funcionais. Boletim da Sociedade Brasileira de Ciência e Tecnologia de Alimentos, Campinas, v. 5, n. 31, p. 200-206, 1997.

[26] PINHEIRO, M. V. S. Caracterização de iogurtes fabricados com edulcorantes, fermentados por cultura láctica probiótica. 2003. 196f. Dissertação (Mestrado em Engenharia e Ciência de Alimentos) - IBILCE / UNESP, São José do Rio Preto, 2003.

[27] PUPIN, A. M. Probióticos, prebióticos e simbióticos: aplicações em alimentos funcionais. Seminário Novas Alternativas de Mercado - ITAL, Campinas, p. 133-145, 2002.

[28] SANTOS, J. P. V., FERREIRA, C. L. L. F. Alternativas para o aproveitamento de soro de queijo nos pequenos e médios laticínios. Revista do Instituto de Laticínios Cândido Tostes, Juiz de Fora, v. 56, n. 3, p. 44-50, 2001.

[29] SGARBIERI, V. C., PACHECO, M. T. B. Revisão: Alimentos funcionais fisiológicos. Brazilian Journal of Food Technology, n. 2, p. 7-19, 1999.

[30] SILVA, M. R., FERREIRA, C. L. L. F., COSTA, N. M. B., MAGALHÃES, J. Elaboração e avaliação de uma bebida láctea fermentada à base de soro de leite fortificada com ferro. Revista do Instituto de Laticínios Cândido Tostes, Juiz de Fora, v. 56, n. 3, p. 7-14, 2001.

[31] SILVA, P. H. F., PEREIRA, D. B. C., OLIVEIRA, L. L., COSTA JÚNIOR, L.C.G. Físico-Química do Leite e Derivados: Métodos Analíticos. Juiz de Fora: Oficina de Impressão, 1997. 190p.
[32] SOUZA, G. Fatores que controlam o corpo e textura de iogurtes comerciais. Coletânea do Instituto de Tecnologia de Alimentos, Campinas, v. 20, n. 2, p. 105-110, 1990.

[33] TAMIME, A. Culturas "starter" lácticas e probióticas. In: LERAYER, A. L. S., SALVA, T. J. G., coords. Leites fermentados e bebidas lácticas. Campinas: ITAL, p. 2.11-2.25, 1997.

[34] TAMIME, A. Y., DEETH, H. C. Yogurt: technology and biochemistry. Journal of Food Protection, Ames, v. 43, n. 12, p. 939-971, 1980.

[35] TAMIME, A. Y., ROBINSON, R. K. Yogurt: Ciencia y Tecnologia. Zaragoza: Acribia, 1991. 368p.

[36] TOMOMATSU, H. Health effects of oligosaccharides. Food Technology, Chicago, v. 48, n. 10, p. 61-65, 1994.

[37] TRONCO, V. M. Manual para Inspeção da Qualidade do Leite. Santa Maria - RS: Editora da Universidade Federal de Santa Maria, 1997. 166p.

[38] USDEC - UNITED STATES DAIRY EXPORT COUNCIL. Características, funções e novas aplicações das proteínas de soro e suas novas frações. Food Ingredients, São Paulo, n. 17, p. 50-56, 2002.

[39] VINDEROLA, C. G., BAIlo, N., REINHEIMER, J. A. Survival of probiotic in Argentina yogurts during refrigerate storage. Food Research International, Barking, v. 33, n. 2, p. 97-102, 2000.

[40] WOLFSCHOON-POMBO, A. F., GRANZINOLLI, G. G. M., FERNANDES, R. M. Sólidos totais do leite, acidez, $\mathrm{pH}$ e viscosidade do iogurte. Revista do Instituto de Laticínios Cândido Tostes, Juiz de Fora, v. 227, n. 37, p. 19-24, 1983.

\section{6 - AGRADECIMENTOS}

Os autores agradecem à Fundação de Amparo à Pesquisa do Estado de São Paulo (FAPESP) pelo suporte financeiro. 